\title{
Am I my brother's keeper? A survey of 10 healthcare professions in the Netherlands about experiences with impaired and incompetent colleagues
}

\author{
Jan Willem Weenink, ${ }^{1}$ Gert P Westert, ${ }^{1}$ Lisette Schoonhoven, ${ }^{1,2}$ \\ Hub Wollersheim, ${ }^{1}$ Rudolf B Kool ${ }^{1}$
}

\section{${ }^{1}$ Scientific Institute for Quality of Healthcare (IQ healthcare), Radboud University Medical Center, Nijmegen, The Netherlands \\ ${ }^{2}$ Faculty of Health Sciences, University of Southampton, Southampton, UK}

\section{Correspondence to} Scientific Institute for Quality of Healthcare (IQ healthcare), Radboud University Medical Center, Jan-Willem Weenink, P.O. Box 9101, Nijmegen 6500 HB, The Netherlands; janwillemweenink@gmail.com

Received 27 March 2014 Revised 9 October 2014 Accepted 20 October 2014 Published Online First 7 November 2014

\section{CrossMark}

\author{
To cite: Weenink JW, \\ Westert GP, Schoonhoven L, \\ et al. BMJ Qual Saf \\ 2015:24:56-64.
}

\begin{abstract}
Background Dealing with poor individual performance of healthcare professionals is essential in patient safety management. The objective of the current study was to explore potential differences regarding experiences with impaired and incompetent colleagues between a broad range of healthcare professions.

Methods A survey of 10 legally regulated professions in the Netherlands on knowledge on dealing with impaired/incompetent colleagues, experiences with such colleagues, action taken upon an impaired and incompetent colleague and reasons for not taking action.

Results We approached 4348 professionals, of whom 1238 responded (28.5\%). One-third of the respondents (31.3\%) had an experience with an impaired or incompetent colleague in the preceding 12 months, and $84 \%$ of these reported cases concerned incompetence. Even under the extreme assumption that all nonrespondents had no such experiences, our results indicate that at least $9 \%$ of the total sample had dealt with an impaired or incompetent colleague in the previous 12 months. Two-thirds of the professionals (68.6\%) who had an experience reported having acted upon it. Respondents significantly less often reported to have acted ( $49.6 \%$ vs $79.1 \%, p=0.000)$ when the colleague was working at a different organisation. The primary reason for not taking action was that impairment/incompetence could not be proven. Conclusions Even using an extreme correction for our low response rate, at least $9 \%$ of healthcare professionals reported dealing with impaired or incompetent colleagues in the past year. Creating and clarifying reporting opportunities when confronted with an incompetent or impaired colleague should be a
\end{abstract}

priority for professional organisations, policymakers and regulatory bodies.

\section{BACKGROUND}

Poor individual performance of healthcare professionals can have serious implications for patient safety. ${ }^{1}$ From the many underlying causes, distinction is made between impairment and incompetence. ${ }^{2}$ Impairment includes substance abuse, mental or physical illness and disruptive behaviour; ${ }^{3}$ incompetence concerns a deficiency in knowledge or skills and may include interpersonal skills such as communication and collaboration problems. ${ }^{4} 5$ These conditions frequently overlap. ${ }^{6}$ While it is hard to accurately determine the prevalence of poor performance among professionals, several studies have estimated the prevalence of single causes of such performance, such as substance abuse, ${ }^{7} 8$ disruptive behaviour $^{9}$ and mental illness. ${ }^{10}$ Considering all forms of poor individual performance, it has been estimated that at least one-third of all physicians will be confronted with a period in their career during which they have a condition that impairs their ability to practice medicine safely. $^{1}$

Dealing with impaired and incompetent healthcare professionals is essential in patient safety management. Giving critical feedback and daring to discuss risks for patient safety is increasingly considered a crucial and necessary step in improving safety culture. ${ }^{11}$ Assessing the willingness of healthcare professionals to discuss poor performance is, therefore, 
important. Moreover, healthcare professionals have an ethical, and in some countries legal, responsibility to address performance problems of other healthcare professionals. ${ }^{4} 12$ Recent studies showed that 64\%$77 \%$ of physicians are willing to report impaired or incompetent colleagues to relevant authorities. ${ }^{2} 13$ When faced with such colleagues in real life, however, $33 \%-45 \%$ of physicians did not report them, which raises questions about the ability of medicine to self-regulate. $^{2} 14$

Previous studies of individual performance problems mainly focused on physicians. ${ }^{11} 1516$ However, delivering high-quality care often requires cooperation between different healthcare professions. ${ }^{17}$ To the best of our knowledge, no research has been done to identify experiences with and willingness to report incompetent and impaired colleagues from other healthcare professions. In this explorative study, we present the results of a large national survey focusing on potential differences between 10 professions regarding experiences with impaired and incompetent colleagues. We also examine if, and how, professionals acted upon such experiences. With this study we aim to provide further insight in the ability of healthcare professions to self-regulate. It may also serve as valuable input for patient safety policy aimed at timely action with regards to impaired and incompetent professionals.

\section{METHODS}

\section{Study design}

We developed a questionnaire based on existing literature $^{2} 14$ and adjusted a first draft following feedback of expert colleagues and involved professional associations. A second draft questionnaire was pilot-tested by two healthcare professionals from each included profession $(n=18)$ in order to determine that questions were clear, whether any important topics were missing and to ensure face validity. These professionals were recruited from our own professional network. We included a definition of impairment/ incompetence on the title page of the questionnaire, which incorporated four key aspects as follows: impairment/incompetence concerns a (1) structural situation, (2) of irresponsible healthcare delivery, (3) which is (potentially) hazardous to the patient and (4) in which the specific healthcare professional is not able or willing to recover by himself or herself. ${ }^{18}$ A comment was included that this could involve substance abuse or disruptive behaviour.

The finalised questionnaire recorded respondents' general characteristics and queried their knowledge of and confidence in dealing with impaired/incompetent colleagues from both the same and different healthcare professions, who work at the same or at a different organisation. Answers were given on a five-point Likert scale ranging from 'totally disagree' to 'totally agree'. We defined respondents who answered 'agree' or 'totally agree' as having knowledge and confidence in concordance with the question. The questionnaire also asked about experiences with an impaired or incompetent colleague in the preceding 12 months. A 'colleague' was defined as being a professional from one of the professions included in our study, who worked either at the same practice as the respondent or at another one. If respondents had experienced an impaired/incompetent colleague, we asked about the profession of this colleague, the cause(s) of impairment/incompetence and the reaction of the respondent to this experience. If respondents had experienced more than one impaired or incompetent colleague in the past 12 months, we asked about the most recent case. A second part of the questionnaire focused on the instruments and tools available and required in order that professionals are able to adequately deal with impaired and incompetent colleagues; on methods used by healthcare professionals to assess their own competence and on the responsibilities of different stakeholders in dealing with impaired and incompetent professionals. This part of the questionnaire further included three hypothetical case scenarios. The results of this second part are not included in this study.

Questionnaires were sent by email along with a joint introduction from the specific professional association and our research institute. A reminder to complete the questionnaire was sent after two and a half weeks.

\section{Study population}

Our study population included dentists, midwives, nurses, pharmacists, physicians, physiotherapists, psychologists and psychotherapists. These are the legally regulated professions in the Netherlands. 'Physicians' was further segregated into 'general practitioners' (GPs), 'medical specialists' and 'elderly care physicians' due to their different roles in Dutch healthcare -namely primary care, secondary healthcare and long-term care. Professionals were randomly selected from the member data of each professional association. For medical specialists, we used a representative random sample based on the number of professionals of each specialty in the Netherlands. No exclusion criteria were used. Respondents were, however, only included in our analysis if they indicated at the start of the questionnaire that they were currently working in patient care.

Our aim at the outset of the study was to approach 400 professionals from each included profession with the assistance of each specific professional association. In consultation with and at the request of the professional associations, we invited 800 GPs and psychotherapists, 448 dentists and 300 midwives. For nurses it was not possible to draw a random sample from the member data of the professional association. Instead, a publicly accessible questionnaire was issued through the association's newsletter. 


\section{Setting}

This study focuses on dealing with impaired and incompetent professionals in the Netherlands. Self-regulation, particularly of the medical profession, is an important aspect of the Dutch system. ${ }^{19}$ Healthcare professionals are assumed to act upon circumstances (including concerns about an individual provider) that may threaten patient safety, following professional standards, legal regulation or prescribed ethical codes. ${ }^{18}{ }^{20}$ Furthermore, healthcare providers are responsible for the performance of individual professionals within their organisation. ${ }^{21}$ The Health Care Inspectorate has set minimum standards that act as an accountability mechanism in the form of accreditation. ${ }^{19}$ The Health Care Inspectorate may itself look into concerns regarding individual healthcare professionals at its own instigation. Professional associations can look into a concern when the healthcare provider of concern is a member, a case may be filed to one of the independent judicial courts and the public prosecution service may start an investigation when it concerns a criminal matter. ${ }^{22-24}$

\section{Data analysis}

We used univariate and bivariate analyses to examine differences between professions on three aspects:

- knowledge on how to deal with impaired/incompetent colleagues

- experiences with such colleagues in the past 12 months

- the respondent's reactions upon those experiences.

We looked specifically into experiences involving a colleague from the same profession as the respondent as opposed to those of another profession in order to explore to what extent interprofessional issues could be affecting reactions to impairment/incompetence. We also explored whether there were differences in action taken towards impaired/incompetent professionals within or outside the own organisation. Since previous papers focused on formal actions in dealing with impaired and incompetent colleagues, we also explored differences between the situations where the respondent took informal as opposed to formal action. Formal action was defined as reporting the experience to the board of the organisation, the medical association, the Health Care Inspectorate, one of the independent judicial courts or to the public prosecution service. We compared the experiences of those respondents who only took informal action with those who undertook formal action (including situations where the respondent took both formal and informal action).

We used SPSS V.20.0 for all analyses.

\section{RESULTS}

We approached 4348 professionals, of whom 1238 responded $(28.5 \%)$. Response rate by healthcare profession varied from $17.0 \%$ (pharmacists) to $45.5 \%$ (elderly care physicians). At the start of the questionnaire, 80 professionals indicated that they were currently not practising as a healthcare professional and were, therefore, ineligible. Furthermore, 119 nurses responded to the questionnaire in the newsletter, giving a total of 1277 professionals included in the study results.

Characteristics of our study population are listed in table 1 . Almost $63 \%$ of respondents were women; the average age was 49 years (SD 11.3) and the average number of years in practice was 18 years (SD 10.1). More than half of the respondents worked in an independent practice $(57 \%)$, and a majority worked with colleagues of the same profession (80\%). About $40 \%$ of

Table 1 Characteristics of respondents

\begin{tabular}{|c|c|c|}
\hline & \multicolumn{2}{|c|}{ Study population } \\
\hline & $\mathrm{N}$ & $\%$ \\
\hline \multicolumn{3}{|l|}{ Gender $(n=1271)$} \\
\hline Male & 475 & 37.4 \\
\hline Female & 796 & 62.6 \\
\hline \multicolumn{3}{|l|}{ Age (years) $(n=1270)$} \\
\hline$\leq 30$ & 81 & 6.4 \\
\hline $30-39$ & 219 & 17.2 \\
\hline $40-49$ & 295 & 23.2 \\
\hline $50-59$ & 469 & 36.9 \\
\hline$\geq 60$ & 206 & 16.2 \\
\hline \multicolumn{3}{|l|}{ Profession $(n=1277)$} \\
\hline Dentist & 98 & 7.7 \\
\hline Elderly care physician & 152 & 11.9 \\
\hline General practitioner & 236 & 18.5 \\
\hline Midwife & 119 & 9.3 \\
\hline Medical specialist & 99 & 7.8 \\
\hline Nurses & 119 & 9.3 \\
\hline Pharmacist & 68 & 5.3 \\
\hline Physiotherapist & 100 & 7.8 \\
\hline Psychologist & 98 & 7.7 \\
\hline Psychotherapist & 188 & 14.7 \\
\hline \multicolumn{3}{|l|}{ Years in practice $(n=1252)$} \\
\hline$<10$ & 301 & 24.0 \\
\hline $10-19$ & 396 & 31.6 \\
\hline $20-29$ & 352 & 28.1 \\
\hline$\geq 30$ & 203 & 16.2 \\
\hline \multicolumn{3}{|l|}{ Type of organisation $(n=1232)$} \\
\hline Hospital & 170 & 13.8 \\
\hline Mental healthcare organisation & 46 & 3.7 \\
\hline Nursing home & 172 & 14.0 \\
\hline Community health centre & 93 & 7.5 \\
\hline Independent practice & 703 & 57.1 \\
\hline Other & 48 & 3.9 \\
\hline \multicolumn{3}{|l|}{ Colleagues of same profession $(n=1270)$} \\
\hline No & 249 & 19.6 \\
\hline W/ colleague(s) of same profession & 1021 & 80.4 \\
\hline \multicolumn{3}{|c|}{ Salaried instead of self-employed $(n=1270)$} \\
\hline No & 766 & 60.3 \\
\hline Yes & 504 & 39.7 \\
\hline
\end{tabular}


Table 2 Knowledge and confidence to deal with impaired/incompetent colleagues*

\begin{tabular}{|c|c|c|c|c|c|c|c|c|}
\hline & \multicolumn{2}{|c|}{$\begin{array}{l}\text { Of same } \\
\text { profession at } \\
\text { same } \\
\text { organisationt }\end{array}$} & \multicolumn{2}{|c|}{$\begin{array}{l}\text { Of same profession } \\
\text { at different } \\
\text { organisation }\end{array}$} & \multicolumn{2}{|c|}{$\begin{array}{l}\text { Of another } \\
\text { profession at same } \\
\text { organisation }\end{array}$} & \multicolumn{2}{|c|}{$\begin{array}{l}\text { Of another } \\
\text { profession at } \\
\text { different } \\
\text { organisation }\end{array}$} \\
\hline & $\mathrm{N}$ & $\%$ & $\mathrm{~N}$ & $\%$ & $\mathrm{~N}$ & $\%$ & $\mathrm{~N}$ & $\%$ \\
\hline Total & $706 / 980$ & 72.0 & $337 / 1115$ & 30.2 & $520 / 1067$ & 51.3 & $263 / 1125$ & 23.4 \\
\hline \multicolumn{9}{|l|}{ Gender } \\
\hline Male & 294 & 80.5 & 155 & 37.0 & 229 & 57.1 & 111 & 26.2 \\
\hline Female & 412 & 67.0 & 182 & 26.1 & 318 & 47.7 & 152 & 21.7 \\
\hline \multicolumn{9}{|l|}{ Age (years) } \\
\hline$\leq 30$ & 49 & 70.0 & 14 & 19.7 & 27 & 38.0 & 12 & 16.7 \\
\hline $30-39$ & 118 & 65.6 & 41 & 21.4 & 79 & 42.0 & 32 & 16.7 \\
\hline $40-49$ & 175 & 70.6 & 65 & 24.4 & 134 & 50.6 & 56 & 20.9 \\
\hline $50-59$ & 257 & 73.6 & 133 & 33.2 & 204 & 53.5 & 95 & 23.5 \\
\hline$\geq 60$ & 107 & 80.5 & 84 & 45.4 & 103 & 63.6 & 68 & 36.0 \\
\hline \multicolumn{9}{|l|}{ Profession } \\
\hline Dentist & 49 & 71.0 & 24 & 29.6 & 37 & 49.3 & 18 & 22.0 \\
\hline Elderly care physician & 92 & 66.7 & 20 & 14.3 & 81 & 57.9 & 14 & 10.0 \\
\hline General practitioner & 143 & 71.5 & 79 & 37.4 & 111 & 52.4 & 48 & 22.5 \\
\hline Midwife & 71 & 65.1 & 31 & 27.7 & 48 & 43.6 & 28 & 24.8 \\
\hline Medical specialist & 61 & 71.8 & 28 & 32.6 & 44 & 51.2 & 18 & 20.5 \\
\hline Nurses & 64 & 81.0 & 23 & 29.9 & 44 & 55.0 & 26 & 33.8 \\
\hline Pharmacist & 35 & 87.5 & 14 & 26.4 & 17 & 34.0 & 10 & 18.2 \\
\hline Physiotherapist & 58 & 64.4 & 18 & 18.9 & 33 & 35.5 & 15 & 15.8 \\
\hline Psychologist & 49 & 80.3 & 32 & 36.8 & 43 & 55.1 & 27 & 30.0 \\
\hline Psychotherapist & 84 & 77.1 & 68 & 39.3 & 89 & 62.2 & 59 & 34.3 \\
\hline \multicolumn{9}{|l|}{ Years in practice } \\
\hline$<10$ & 169 & 66.8 & 64 & 24.5 & 112 & 43.8 & 44 & 16.8 \\
\hline 10-19 & 232 & 74.1 & 103 & 28.8 & 181 & 53.2 & 86 & 24.0 \\
\hline $20-29$ & 184 & 71.0 & 106 & 35.0 & 149 & 50.9 & 77 & 25.0 \\
\hline$\geq 30$ & 110 & 78.6 & 59 & 33.5 & 94 & 58.4 & 50 & 27.9 \\
\hline \multicolumn{9}{|l|}{ Type of organisation } \\
\hline Hospital & 100 & 68.5 & 38 & 26.2 & 72 & 48.6 & 31 & 21.1 \\
\hline Mental healthcare organisation & 33 & 82.5 & 10 & 22.7 & 31 & 70.5 & 11 & 25.0 \\
\hline Nursing home & 105 & 70.9 & 27 & 17.9 & 89 & 59.7 & 20 & 13.3 \\
\hline Community health centre & 59 & 75.6 & 27 & 32.9 & 40 & 47.1 & 19 & 22.6 \\
\hline Independent practice & 361 & 71.3 & 216 & 34.5 & 281 & 49.0 & 165 & 26.1 \\
\hline Other & 27 & 77.1 & 9 & 22.5 & 20 & 50.0 & 8 & 20.0 \\
\hline \multicolumn{9}{|l|}{ Colleagues of same profession } \\
\hline No & 49 & 62.0 & 83 & 39.5 & 77 & 46.7 & 70 & 32.0 \\
\hline W/ colleague(s) same profession & 657 & 72.9 & 254 & 28.1 & 470 & 52.1 & 193 & 21.3 \\
\hline \multicolumn{9}{|l|}{ Salaried instead of self-employed } \\
\hline No & 412 & 73.2 & 238 & 34.9 & 314 & 49.8 & 174 & 25.3 \\
\hline Yes & 294 & 70.5 & 99 & 22.9 & 233 & 53.4 & 89 & 20.4 \\
\hline
\end{tabular}

*Percentages are based on valid cases and are unadjusted.

†A comment was included that if the respondent was not working with professionals of the same profession, this could be left blank.

respondents were professionals on the payroll of an organisation as opposed to self-employed professionals.

\section{Knowledge of dealing with impaired and incompetent colleagues}

Almost three-quarters of the respondents (72.0\%) indicated they agreed or totally agreed that they knew how to deal with impaired and incompetent colleagues of the same profession working at their own organisation (table 2). Half of the respondents $(51.3 \%)$ knew how to deal with impaired/incompetent colleagues of a different profession working at the same organisation, while less than one-third (30.2\%) knew how to deal with impaired/incompetent 
colleagues of the same profession working at a different organisation and less than a quarter of the respondents (23.4\%) indicated that they knew how to deal with colleagues of another profession working at a different organisation.

\section{Experiences with an impaired or incompetent colleague}

Almost one-third of the respondents (31.3\%) had an experience with an impaired or incompetent colleague in the preceding 12 months (table 3 ). Overall, 66.4\% of the reported cases concerned incompetence, $13.2 \%$ impairment and the remaining $20.4 \%$ a combination of both. In a majority of the reported cases, it concerned two or more causes of impairment/incompetence $(57.2 \%)$. The specific underlying causes are listed in table 4, with substandard care mentioned most often $(57.2 \%)$.

\section{Description of action taken}

Two-thirds of respondents (68.6\%) indicated that they acted upon the experience. Elderly care physicians (84.1\%), nurses (83.3\%) and medical specialists $(82.9 \%)$ most often reported to have taken action, and dentists (42.9\%) and physiotherapists (47.4\%) least often reported to have taken action. Actions mainly concerned 'talking to the impaired/incompetent colleague' $(71.4 \%)$ and 'discussing the experience with colleagues' (58.3\%). A small percentage reported the colleague to the board of the organisation $(11.7 \%)$, the professional association $(3.0 \%)$ or the Health Care Inspectorate (6.0\%). In total, 213 respondents reported to have taken informal action $(82.7 \%)$, while 8 took formal action (3.0\%) and 38 took both informal and formal action (14.3\%). No significant differences in causes of impairment or incompetence were observed between respondents who took formal action and those who only took informal action. Respondents who undertook formal action more often reported to have knowledge on how to deal with impaired/incompetent colleagues of the same profession within their organisation $(94.9 \%$ vs $76.7 \%, \mathrm{p}=0.010)$ and colleagues of another profession outside their own organisation $(50.0 \%$ vs $29.1 \%$, $\mathrm{p}=0.011$ ). Furthermore, respondents who took formal action more often reported that there was a risk for patient safety $(60.9 \%$ vs $39.2 \%, \mathrm{p}=0.007)$.

\section{Results of action taken}

Actions taken resulted in the colleague 'being talked to about the impairment/incompetence' in more than half of the cases $(58.6 \%)$, 'starting an improvement trajectory' in $29.3 \%$, and in the colleague leaving the current employment in about a quarter of instances (24.1\%). Hardly any action led to a complaint to the disciplinary court $(1.9 \%)$ or to the start of a criminal investigation $(0.8 \%)$. About a tenth of the respondents $(12.4 \%)$ reported that their actions had led to nothing.
Table 3 Experiences with an impaired or incompetent colleague* $^{*}$

\begin{tabular}{|c|c|c|c|c|}
\hline & \multicolumn{2}{|c|}{$\begin{array}{l}\text { Experience } \\
\text { with impaired/ } \\
\text { incompetent } \\
\text { colleague }\end{array}$} & \multicolumn{2}{|c|}{$\begin{array}{l}\text { Acted upon } \\
\text { experience of } \\
\text { impaired/ } \\
\text { incompetent } \\
\text { colleague }\end{array}$} \\
\hline & $\mathrm{N}$ & $\%$ & $\mathrm{~N}$ & $\%$ \\
\hline Total & $390 / 1248$ & 31.3 & $266 / 388$ & 68.6 \\
\hline \multicolumn{5}{|l|}{ Gender } \\
\hline Male & 140 & 29.7 & 101 & 72.7 \\
\hline Female & 250 & 32.2 & 165 & 66.3 \\
\hline \multicolumn{5}{|l|}{ Age (years) } \\
\hline$\leq 30$ & 36 & 46.2 & 20 & 55.6 \\
\hline $30-39$ & 66 & 31.1 & 43 & 65.2 \\
\hline $40-49$ & 92 & 31.3 & 65 & 71.4 \\
\hline $50-59$ & 143 & 31.2 & 105 & 73.4 \\
\hline$\geq 60$ & 53 & 26.0 & 33 & 63.5 \\
\hline \multicolumn{5}{|l|}{ Profession } \\
\hline Dentist & 28 & 29.2 & 12 & 42.9 \\
\hline Elderly care physician & 45 & 30.0 & 37 & 84.1 \\
\hline General practitioner & 74 & 31.6 & 46 & 62.2 \\
\hline Midwife & 37 & 31.4 & 22 & 59.5 \\
\hline Medical specialist & 36 & 37.1 & 29 & 82.9 \\
\hline Nurses & 78 & 73.6 & 65 & 83.3 \\
\hline Pharmacist & 13 & 19.4 & 9 & 69.2 \\
\hline Physiotherapist & 19 & 19.4 & 9 & 47.4 \\
\hline Psychologist & 20 & 20.6 & 13 & 65.0 \\
\hline Psychotherapist & 40 & 21.6 & 24 & 60.0 \\
\hline \multicolumn{5}{|l|}{ Years in practice } \\
\hline$<10$ & 98 & 33.4 & 60 & 61.9 \\
\hline $10-19$ & 110 & 28.3 & 75 & 68.2 \\
\hline $20-29$ & 104 & 29.9 & 73 & 70.9 \\
\hline$\geq 30$ & 71 & 35.7 & 53 & 74.6 \\
\hline \multicolumn{5}{|l|}{ Practice organisation } \\
\hline Hospital & 81 & 49.1 & 64 & 80.0 \\
\hline Mental healthcare organisation & 16 & 34.8 & 12 & 75.0 \\
\hline Nursing home & 59 & 34.9 & 50 & 86.2 \\
\hline Community health centre & 31 & 33.3 & 19 & 61.3 \\
\hline Independent practice & 159 & 22.8 & 88 & 55.3 \\
\hline Other & 21 & 46.7 & 15 & 71.4 \\
\hline \multicolumn{5}{|l|}{ Colleagues of same profession } \\
\hline No & 46 & 18.7 & 26 & 56.5 \\
\hline $\begin{array}{l}\text { W/colleague(s) of same } \\
\text { profession }\end{array}$ & 344 & 34.3 & 240 & 70.2 \\
\hline \multicolumn{5}{|l|}{ Salaried instead of self-employed } \\
\hline No & 201 & 26.5 & 118 & 59.0 \\
\hline Yes & 189 & 38.6 & 148 & 78.7 \\
\hline
\end{tabular}

${ }^{*}$ Percentages are based on valid cases and are unadjusted.

\section{Reasons for not taking action}

The main reason for not taking action was that impairment/incompetence could not be proven (38.5\%). Other reasons included that others had already taken action $(25.4 \%)$, due to possible consequences for the 


\begin{tabular}{|c|c|c|c|c|}
\hline & \multicolumn{2}{|c|}{$\begin{array}{l}\text { Characteristics impaired or } \\
\text { incompetent colleague }\end{array}$} & \multicolumn{2}{|c|}{$\begin{array}{l}\text { Acted upon experience of } \\
\text { impaired/incompetent } \\
\text { colleague }\end{array}$} \\
\hline & $\mathrm{N}$ & $\%$ & $\mathrm{~N}$ & $\%$ \\
\hline$\overline{\text { Total }}$ & 390 & & $266 / 388$ & 68.6 \\
\hline \multicolumn{5}{|l|}{ Professional } \\
\hline Of same profession & 255 & 77.5 & 174 & 68.2 \\
\hline Of another profession & 74 & 22.5 & 45 & 60.8 \\
\hline \multicolumn{5}{|l|}{ Organisation } \\
\hline In my practice or organisation & 230 & 64.6 & 182 & 79.1 \\
\hline Outside my organisation & 126 & 35.4 & 62 & 49.6 \\
\hline \multicolumn{5}{|l|}{ Patient safety at risk } \\
\hline No/l don't know & 251 & 65.0 & 154 & 61.4 \\
\hline Yes & 135 & 35.0 & 111 & 82.2 \\
\hline Cause of incompetencet & 328 & 84.1 & 222 & 67.7 \\
\hline Substandard care & 223 & 57.2 & 149 & 66.8 \\
\hline Collaboration problems with colleagues & 156 & 40.0 & 114 & 73.1 \\
\hline Communication problems with colleagues & 159 & 40.8 & 122 & 76.7 \\
\hline Communication problems with patients & 120 & 30.8 & 89 & 74.2 \\
\hline Cause of impairment $\dagger$ & 127 & 32.6 & 95 & 74.8 \\
\hline Substance abuse (eg, drugs or alcohol) & 33 & 8.5 & 22 & 66.7 \\
\hline Disruptive behaviour & 56 & 14.4 & 39 & 69.6 \\
\hline Physical impairment & 18 & 4.6 & 15 & 83.3 \\
\hline Mental illness & 39 & 10.0 & 35 & 89.7 \\
\hline
\end{tabular}

*Percentages are based on valid cases and are unadjusted.

tMultiple causes could be checked, impairment and incompetence may overlap.

team climate $(23.0 \%)$, because it was unknown what actions to take $(20.5 \%)$ and because it was considered to be the responsibility of others (17.2\%).

\section{Interprofessional experiences}

Of respondents who specified the profession of the impaired/incompetent colleague $(n=329)$, threequarters indicated that the colleague was of the same profession (77.5\%). For colleagues of another profession, mental illness as a cause was less often reported $(2.7 \%$ vs $12.5 \%, p=0.014)$. No significant differences were observed between the groups regarding acting upon the experience. When acting upon the experience, it was less often discussed with the colleague himself when it concerned a colleague of another profession $(51.1 \%$ vs $75.3 \%, p=0.002)$.

\section{Interorganisational experiences}

Of respondents who specified whether the impaired/ incompetent colleague worked at the same or at a different organisation $(n=356)$, almost two-thirds indicated that the colleague was from the same organisation $(64.6 \%)$. For colleagues from another organisation, experiences less often concerned collaboration problems (30.2\% vs $46.5 \%, p=0.003)$ or communication problems $(33.3 \%$ vs $47.4 \%, \mathrm{p}=0.010)$ with colleagues. Respondents who experienced an impaired/incompetent colleague from another organisation less often reported to have acted upon the experience $(49.6 \%$ vs $79.1 \%$, $\mathrm{p}=0.000)$. Of those who acted upon it, it was more usually discussed with colleagues not directly working with $(16.1 \%$ vs $5.5 \%, \mathrm{p}=0.009)$ or reported to the Health Care Inspectorate $(12.9 \%$ vs $2.2 \%, \mathrm{p}=0.001)$. Less often it was discussed with colleagues directly working with $(41.9 \%$ vs $64.8 \%, \mathrm{p}=0.002)$, the supervisor $(11.3 \%$ vs $52.2 \%, \mathrm{p}=0.000)$ or the medical staff $(1.6 \%$ vs $12.6 \%, \mathrm{p}=0.012)$.

\section{DISCUSSION}

Almost three-quarters (72\%) of healthcare professionals report to have knowledge on how to handle situations regarding an impaired or incompetent colleague of the same profession within their own organisation, whereas $51 \%$ of professionals report so when it concerns a professional from a different profession. Professionals even less often reported to have knowledge on how to handle the situation when it concerns a colleague outside their own organisation, with $30 \%$ of professionals reporting to have this knowledge for colleagues of the same profession and $23 \%$ for colleagues of another profession. Almost one-third of the healthcare professionals indicated that they actually had an experience with an impaired or incompetent 
colleague in the preceding year, and of those two-third reported to have taken action.

Today, providing good quality healthcare often demands collaboration between professionals across organisations. ${ }^{25}$ This seems to be confirmed by our finding that more than one-third of reported experiences concerned a colleague working at a different practice or organisation. Professionals report to have limited knowledge on how to deal with such colleagues. They less often report to have acted upon an experience of incompetence or impairment in relation to a colleague working at a different organisation. No notable differences in reasons for not taking action were observed between professionals who experienced an impaired/incompetent colleague at their own organisation and professionals who experienced such a colleague outside their own organisation. This indicates that attention should be paid to dealing with impaired and incompetent professionals working at a different organisation. About a quarter of the experiences concerned a colleague of another profession, though our results suggest that dealing with interprofessional experiences is not very different from dealing with colleagues from the same profession.

For all professions, a substantial amount of professionals reported to have experienced an impaired/ incompetent colleague in the past 12 months. Previous studies have recorded percentages slightly lower than 20 for a 3-year period, but these studies only considered colleagues working at the same practice or organisation. $^{2}{ }^{16}$ It is important to realise that this figure does not in itself demonstrate the prevalence of impairment or incompetence among healthcare professionals. It does, however, highlight that dealing with impairment and incompetence is an issue for all Dutch healthcare professions, not just for physicians. Nurses reported more than twice having this experience. We did observe differences between professions regarding knowledge on how to deal with impaired/incompetent colleagues and in acting upon such a colleague. Pharmacists were most likely to report that they knew how to deal with impaired/incompetent colleagues of the same profession at their organisation, and psychotherapists most often reported to know how to deal with colleagues at a different organisation. Medical specialists were among the most likely to act upon an impaired or incompetent colleague, which could be caused by the explicit protocol of the professional association on how to deal with impaired and incompetent professionals. ${ }^{26}$ We did not, however, observe a difference in their reported knowledge on how to deal with impairment or incompetence. Neither did we observe that GPs were more likely to report, though their association has a protocol on how to deal with impaired/ incompetent colleagues as well, ${ }^{27}$ while for elderly care physicians and nurses there is no protocol available and they did often report to have acted. Further research is needed to determine whether the availability of profession-specific guidelines and protocols is associated with being prepared and taking action.

Figures on acting upon the impaired colleague are similar to previous studies (about two-third), though these studies focused on reporting to relevant authorities. $^{2} 1416$ Our definition of taking action was broader. Respondents in this study indicated that taking action mainly concerned addressing the impaired colleague or discussing the experience with colleagues. One-fifth took formal action and reported the colleague to relevant authorities such as the board of the organisation, the relevant professional association or the Health Care Inspectorate. In our opinion, it is hard to judge whether this percentage is high or low because it depends on the specific situation. Respondents who thought patient safety was at risk and reported to know how to deal with the situation more often reported to have taken formal action.

About one-third of the professionals who experienced an impaired or incompetent colleague reported not to have acted upon it at all. One quarter of the professionals with such an experience did not act upon it because action was already taken by others. Professionals reported that the main reason for not acting upon the experience was that the impairment or incompetence could not be proven. Furthermore, our results show that many healthcare professionals do not know how to deal with impaired/incompetent colleagues outside their organisation and less often report to act upon such an experience. This is especially alarming because continuity of care crossing the boundaries of organisations and professionals is crucial in an era of specialisation, where patients encounter many specialists in different settings. ${ }^{25}$ The number of professionals that did not act upon an impaired or incompetent colleague could be considerably lowered by information about how to report.

Previous research on single causes of poor performance mainly focused on impairment. There are no overall estimates of the prevalence of incompetence. ${ }^{1}$ In our study, $84 \%$ of the reported cases concerned incompetence, of which often multiple causes overlapped. Furthermore, the primary reason reported for not taking action was that impairment/incompetence could not be proven. This demands objective measures to assess incompetence and impairment, and emphasises the importance of steering on performance, which can be achieved by periodic evaluation of competence and performance. The policy of several Dutch professional associations and the Dutch Health Care Inspectorate seems to be in accordance with these findings as they emphasise steering on performance. $^{26} 28$ Several methods exist that have been validated in evaluating competence. ${ }^{29}$ These may be appropriate for assessing incompetence, though other tools or methods may be required for this sole purpose. 
About one-third of the respondents who had an experience reported that patient safety was at risk. The used definition of impairment and incompetence, however, assumes that there is a potential hazard for the patient. ${ }^{18}$ Our observed percentage for experiences with impaired/incompetent colleagues could therefore be an overestimation. Nonetheless, we think it would be appropriate if professionals would always act upon a colleague that they suspect of being impaired or incompetent, independently of their estimation of patient safety being explicitly at risk.

This study has several limitations, the most obvious being the low response rate of $28 \%$. However, even using an extremely conservative assumption that none of the non-respondents would have reported any experiences with impaired or incompetent colleagues, our results imply that at least $9 \%$ of health professionals in the Netherlands have experience with an incompetent or impaired colleague within the past year. A second limitation is social desirability. Respondents may have overstated the degree to which they acted on their concerns. Lastly, we included medical specialists as one group, possibly missing the opportunity to elicit different experiences and behaviours across specialties. Previous research in the USA found differences between medical specialties regarding personal knowledge of impaired/incompetent colleagues. ${ }^{2}$

Despite the limitations, this study provides further needed insight in the ability of healthcare professions to self-regulate. We found that one in three professionals had an experience with an impaired or incompetent colleague in the preceding 12 months. Even under the extreme assumption that none of the nonrespondents had such an experience, our results would still suggest that a substantial number of professionals would have knowledge of an impaired or incompetent colleague in any given year. Our study shows that dealing with impaired and incompetent colleagues is a serious issue in a broad range of healthcare professions. This should provide a compelling reason for the urgent attention of professional organisations, policymakers and regulatory bodies in order to create and clarify reporting opportunities when confronted with an incompetent or impaired colleague.

Acknowledgements We would like to thank the participating healthcare professionals, employees of the Dutch Health Care Inspectorate, professional associations, expert colleagues and pilot-members for their participation.

Contributors JWW designed the study, was responsible for data collection and data analysis, and wrote the paper. RBK designed the study, supervised data collection and data analysis, and wrote the paper. GPW, LS and HW supervised design of the study and contributed to the paper. All authors had full access to the data (including statistical reports and tables) in the study and take responsibility for the integrity of the data and the accuracy of the data analysis.

Funding The present study is part of a larger study on identifying impaired and incompetent healthcare professionals, which is funded by The Netherlands Organisation for Health Research and Development (ZonMw), and which is conducted in cooperation with the Dutch Health Care Inspectorate (IGZ). Project number 516001002.

Competing interests None.

Provenance and peer review Not commissioned; externally peer reviewed.

Transparency The lead author (JW) affirms that the manuscript is an honest, accurate and transparent account of the study being reported; that no important aspects of the study have been omitted; and that there were no discrepancies from the study as planned.

\section{REFERENCES}

1 Leape LL, Fromson JA. Problem doctors: is there a system-level solution? Ann Intern Med 2006;144:107-15.

2 DesRoches CM, Rao SR, Fromson JA, et al. Physicians' perceptions, preparedness for reporting, and experiences related to impaired and incompetent colleagues. JAMA 2010;304:187-93.

3 684->3. [No authors listed]. The sick physician. Impairment by psychiatric disorders, including alcoholism and drug dependence. JAMA 1973;223:684-7.

4 [No authors listed]. Report of the AMA Council on Ethical and Judicial Affairs: reporting impaired, incompetent, or unethical colleagues. J Miss State Med Assoc 1992;33:176-7.

5 Epstein RM, Hundert EM. Defining and assessing professional competence. JAMA 2002;287:226-35.

6 Donaldson LJ. Doctors with problems in an NHS workforce. BMJ 1994;308:1277-82.

7 Brewster JM. Prevalence of alcohol and other drug problems among physicians. JAMA 1986;255:1913-20.

8 McCall SV. Chemically dependent health professionals. West J Med 2001;174:50-4.

9 Rosenstein AH, O’Daniel M. Disruptive behavior and clinical outcomes: perceptions of nurses and physicians. Am J Nurs 2005;105:54-64;

10 Tyssen R, Vaglum P. Mental health problems among young doctors: an updated review of prospective studies. Harv Rev Psychiatry 2002;10:154-65.

11 Benn J, Koutantji M, Wallace L, et al. Feedback from incident reporting: information and action to improve patient safety. Qual Saf Health Care 2009;18:11-21.

12 Raising and acting on concerns about patient safety. Manchester: General Medical Council, 2012. http://www.gmcuk.org/static/documents/content/Raising_and_acting_on_ concerns_about_patient_safety_-_English_0914.pdf

13 Farber NJ, Gilibert SG, Aboff BM, et al. Physicians' willingness to report impaired colleagues. Soc Sci Med 2005;61:1772-5.

14 Campbell EG, Regan S, Gruen RL, et al. Professionalism in medicine: results of a national survey of physicians. Ann Intern Med 2007;147:795-802.

15 Donaldson LJ, Panesar SS, McAvoy PA, et al. Identification of poor performance in a national medical workforce over 11 years: an observational study. BMJ Qual Saf 2014;23:147-52.

16 Roland M, Rao SR, Sibbald B, et al. Professional values and reported behaviours of doctors in the USA and UK: quantitative survey. BMJ Qual Saf 2011;20:515-21.

17 D'Amour D, Ferrada-Videla M, San Martin Rodriguez L, et al. The conceptual basis for interprofessional collaboration: core concepts and theoretical frameworks. J Interprof Care 2005;19 (Suppl 1):116-31.

18 KNMG, KNMG Kwaliteitskader medische zorg. 2012, Koninklijke Nederlandsche Maatschappij tot bevordering der Geneeskunst. 
19 Smith PC, Anell A, Busse R, et al. Leadership and governance in seven developed health systems. Health Policy 2012;106:37-49.

20 (NIP), N.I.v.P., Beroepscode voor psychologen. 2012.

21 Kwaliteitswet Zorginstellingen, W.S. Ministerie van Volksgezondheid, Editor. 1996.

22 Wet op de beroepen in de individuele gezondheidszorg, W.S. Ministerie van Volksgezondheid, Editor. 1993.

23 Tuchrechtbesluit BIG, W.S. Ministerie van Volksgezondheid, Editor. 2009.

24 Gezondheidszorg, I.v.d., IGZ-handhavingskader, Richtlijn voor transparante handhaving. 2008.

25 D'Amour D, Goulet L, Labadie JF, et al. A model and typology of collaboration between professionals in healthcare organizations. BMC Health Serv Res $2008 ; 8: 188$.

26 OMS, Model reglement mogelijk disfunctionerend medisch specialist. 2008, Orde van Medisch Specialisten: Utrecht.

27 LHV, Vermeend disfunctioneren huisarts. Een protocol met handvatten voor het oplossen en bespreekbaar maken van vermeend disfunctioneren. 2012, Landelijke Huisartsen Vereniging: Utrecht.

28 Gezondheidszorg, I.v.d., Staat van de Gezondheidszorg 2013. Op weg naar aantoonbaar verantwoord functionerende beroepsbeoefenaren in de zorg. 2013: Utrecht.

29 Overeem K, Faber MJ, Arah OA, et al. Doctor performance assessment in daily practise: does it help doctors or not? A systematic review. Med Educ 2007;41:1039-49. 